\title{
Questões de estilo no exercício da docência na Educação Superior
}

\section{Style Issues in Higher Education Teaching Practice}

Solange Ariati*

Universidade Tecnológica Federal do Paraná, Campus Pato Branco

Pato Branco, Paraná / Brasil

Anselmo Lima**

Universidade Tecnológica Federal do Paraná, Campus Pato Branco

Pato Branco, Paraná / Brasil

\begin{abstract}
RESUMO: Buscamos compreender no presente artigo como cada professor transforma, à sua maneira, o exercício da docência na educação superior. Para isso, evidenciamos a questão do estilo na prática docente e discutimos como essa característica subjetiva do gênero de atividade se relaciona com o desenvolvimento humano. Os dados foram produzidos empregando-se o método de autoconfrontação e analisados de acordo com o referencial teórico da Clínica da Atividade Docente, a qual assume as perspectivas bakhtiniana e vigotskiana. Os resultados mostram que o estilo funciona como uma reformulação/recriação do gênero de atividade. Essa reformulação/recriação pode ser definida como retoques estilísticos advindos da tentativa de superação de dificuldades que o professor encontra ao realizar a atividade docente.
\end{abstract}

PALAVRAS-CHAVE: estilo; docência; desenvolvimento.

ABSTRACT: In this paper we intend to understand how each teacher does, in his own way, his teaching activity in higher education. For this, we put in evidence the style issue in teaching practice and discuss how that subjective characteristic, which belongs to the genre of activity, relates to human development. The data were produced by means of the self-confrontation method, and the analysis was carried out according to the Clinic of Teaching Activity theoretical reference, which draws on the bakhtinian and vygotskian perspectives. The results reveal that style works as repair/recreation of the genre of activity. This repair/ recreation activity can be defined as stylistic retouching motivated by attempts to overcome difficulties that emerge from the concreteness of the teaching activity.

KEYWORDS: style; teaching activity; development.

*solangeariati@hotmail.com

88 selmolima@hotmail.com 


\section{Introdução}

É recorrente que o professor em sala de aula enfrente situações adversas na realização de sua prática docente. Em outras palavras, há dificuldades previstas ou não no curso do desenvolvimento de sua atividade. Esses obstáculos podem ser resultantes da indisciplina dos alunos, das condições materiais precárias da sala, do atendimento às múltiplas demandas discentes sobre o conteúdo ministrado, entre outras inúmeras possibilidades que podem se apresentar como impeditivas à efetivação do trabalho de ensino-aprendizagem.

Neste estudo identificamos momentos em que o planejado, ou previsto, não é suficiente diante das dificuldades enfrentadas durante o exercício docente em sala de aula. Ademais, interessa-nos compreender como os sujeitos envolvidos no referido ambiente, os professores, lidam com essas situações. Pretendemos com isso compreender como essas experiências podem ou não contribuir para o desenvolvimento do indivíduo docente e de seu bem-estar no trabalho e até mesmo para o coletivo de professores no qual esse sujeito está inserido.

Com esse objetivo, nos debruçaremos sobre dados oriundos de uma ação de formação docente continuada realizada em uma instituição pública de ensino superior, que contou com a participação de dois professores pertencentes ao Departamento de Mecânica (cf. LIMA; ALTHAUS, 2012). A análise desses dados, assim como sua produção, tem como base os estudos da Clínica da Atividade Docente (CLOT, 2007; 2010; LIMA, 2016a), que, por sua vez, articulam as teorizações de Bakhtin (2011; 2015) e Vigotski (2007, 1999). Dessa forma, a presente investigação está inserida em uma agenda pertencente à Linguística Aplicada, que, segundo Moita Lopes (2006), deve ser entendida como um campo híbrido/mestiço ou interdisciplinar, cujo objetivo é não ignorar a materialidade complexa de um fenômeno com uma teoria abstrata. Tal articulação decorrente de uma ótica interdisciplinar é justamente o que a Clínica da Atividade Docente propõe quando une o campo da Linguagem com o da Psicologia do Trabalho e o do Desenvolvimento Histórico-Cultural.

Este estudo se organiza em quatro etapas. Na primeira, apresentaremos nossa opção metodológica de produção dos dados. Na segunda, levantaremos os conceitos teóricos necessários. $\mathrm{Na}$ terceira, realizaremos a análise e discussão do material investigado. Na última, sistematizaremos os resultados das análises com o objetivo de compreender a função do estilo na atividade docente. 


\section{Metodologia}

Para a produção dos dados, utilizamos o método de autoconfrontação (cf. FAÏTA, 1996; CLOT, 2010; LIMA, 2016b), proposto pela Clínica da Atividade, que tem por objetivo desenvolver o poder de agir do sujeito trabalhador em seu exercício profissional. Para isso, esse método se vale da observação e da confrontação do sujeito com sua própria atividade, por meio de imagens. Nessa abordagem, o sujeito não é apenas mero informante, pois "não se pode transformar um homem vivo em objeto mudo de um conhecimento conclusivo à revelia" (BAKHTIN, 2015, p. 66). Assim, objetiva-se, ao dialogar com o trabalhador e não sobre ele, respeitar seu papel de especialista em sua atividade e, por conseguinte, produzir uma ação transformadora e durável (CLOT; FAÏTA, 2016).

Os dados analisados neste estudo são oriundos de sessões de autoconfrontação simples realizadas com uma dupla de docentes do Ensino Superior, em uma ação de formação docente continuada. Isso significa que os professores observaram a si próprios por meio de gravações que foram realizadas em uma de suas aulas.

O ponto de partida dessa ação foi uma reunião com o coletivo de professores do Departamento de Mecânica. Nessa ocasião, foram apresentados a proposta de trabalho e os passos de realização do método da pesquisa com o objetivo de que, minimamente, uma dupla de professores se voluntariasse para participação nas autoconfrontações. O resultado foi que nove professores se voluntariaram, superando assim a expectativa inicial. Os dados aqui analisados são, portanto, resultados construídos com professores que formaram uma dupla de voluntários.

A ação de formação docente continuada, na qual foi utilizado o método de autoconfrontação simples, pode ser resumida pelos seguintes passos: 1) indicação pelos professores de uma turma para a observação; 2) visita à turma de alunos a fim de lhes propor a participação nas filmagens de aula e obter deles o consentimento livre e esclarecido; 3) observação de aulas após o consentimento dos alunos; 4) diálogo inicial com o professor sobre as aulas observadas; 5) filmagem de aulas; 6) recorte de um trecho de aproximadamente cinco minutos de uma das aulas filmadas; 7) momento da autoconfrontação, em que o sujeito descreve e analisa a sua atividade junto ao pesquisador, tendo como foco o trecho de aula recortado. 
Para realização dessas etapas, o docente, que aqui identificamos como "Professor A", indicou para a observação e filmagem uma aula sua ministrada no Curso Tecnológico em Manutenção Industrial, denominada "Gerência da Manutenção", a qual compõe a grade do quarto período do Curso. Já o segundo docente, aqui denominado "Professor B", indicou uma de suas aulas ministrada em disciplina optativa no Curso de Engenharia Mecânica, intitulada "Pesquisa Operacional A". Em termos numéricos, a turma do "Professor A" tinha um total de treze acadêmicos e a turma do "Professor B", um total de oito (LIMA; ALTHAUS; ECKER, 2016).

Para possibilitar a análise do material audiovisual produzido por meio da sessão de autoconfrotação simples realizamos sua transcrição. Optamos por não utilizar normas de transcrição específicas da língua falada porque não objetivamos analisar os fenômenos dessa modalidade de produção textual/discursiva, mas sim as temáticas desenvolvidas pelos docentes em situação de autoconfrontação. Por esse motivo, nossa alternativa de procedimento foi a retextualização, isto é, a "passagem do texto falado para o texto escrito" (MARCUSCHI, 2008, p. 46).

Essa passagem foi realizada com base em quatro ${ }^{1}$ operações apontadas por Marcuschi (2008). Na primeira, eliminamos as marcas interacionais, hesitações e partes de palavras iniciadas e não concluídas. Na segunda, introduzimos a pontuação com base na entonação das falas. Na terceira, retiramos repetições, duplicações e redundâncias. Na quarta, reconstruímos estruturas truncadas e realizamos a reordenação sintática. Para executar essa última operação, foi necessário introduzir e retirar alguns elementos. Quando os incluímos, foram colocados entre colchetes; quando os excluímos, marcamos o local no qual foram suprimidos com um item lexical com três pontos entre colchetes.

É importante ressaltar, uma vez mais, que a análise dos dados foi realizada com o material das sessões de autoconfrontação simples. O todo desse material, incluindo as autoconfrontações cruzadas (cf. FAÏTA, 1996; CLOT, 2010; LIMA, 2016b), foi inicialmente analisado por Ecker (2016) e, sob outro ponto de vista, também por Conte (2017).

\footnotetext{
${ }^{1}$ Marcuschi (2008) aponta um total de nove operações, mas somente quatro delas se fizeram aqui necessárias. As não aplicadas neste estudo estão ligadas à organização tópica de trechos extensos com grande alternância de turnos, o que não ocorreu nos trechos selecionados para a análise nesta pesquisa.
} 


\section{Fundamentação teórica}

\subsection{O Prescrito, o realizado e o gênero}

Para compreender as dificuldades que o professor enfrenta em sala é preciso antes entender que elas não acontecem exclusivamente com uma parcela de profissionais, ou seja, não é o caso de que uns as enfrentem e outros não. Pensar o contrário pode acabar por nos levar irresponsavelmente a rotular os profissionais em dois grupos: de um lado, os bons profissionais e, de outro, os maus. Ao inverso disso, o desenvolvimento do profissional em sua atividade é complexo. Sendo assim, não podemos reduzir a compreensão dessa questão a uma simples dualidade, fundamentando-nos em um julgamento de valor.

Para evitar a redução da já mencionada complexidade, é necessário compreender que os empecilhos de uma atividade são provenientes do momento em que ela é colocada em desenvolvimento, ou seja, quando está sendo realizada. Essas dificuldades são inerentes a qualquer atividade humana socialmente organizada. Elas ocorrem devido às circunstâncias concretas da atividade, o que implica sempre uma distância entre o prescrito e o realizado (LIMA, 2010, p. 119). Sendo assim, o que é planejado ou esperado pelo professor não corresponde em sua totalidade ao que acontece em sala de aula.

Um exemplo dessa distância entre o prescrito e o realizado é o momento em que o professor solicita a realização de uma tarefa a seus alunos, o que não resulta imediatamente em uma tarefa feita, mas sim em uma tarefa esperada (SOUZA-e-SILVA, 2003), que, quando não realizada, pode constituir uma dificuldade para o docente.

Essa distância está ligada ao fato de que toda atividade socialmente organizada, inclusive a docente, possui duas facetas, uma social e outra individual (CLOT, 2010). A social é composta por prescrições. No caso da docência, elas são correspondentes a "aspectos institucionais e normativos, quer formais ou informais" (SOUZA-e-SILVA, 2003, p. 02), que direcionam o trabalho dos profissionais da educação sobre o que devem ou não fazer. Essas prescrições equivalem ao lado socialmente conhecido da atividade, do qual o sujeito toma ciência quando entra em contato com determinada função. A segunda faceta da atividade, de caráter individual, corresponde 
ao modo como o sujeito se posiciona para atender às prescrições diante das dificuldades do real.

Visando agregar elementos à compreensão dessas duas facetas da atividade, Clot (2007) se baseia em Bakhtin (2011) para propor uma "abordagem da atividade em situação do ponto de vista do gênero" (2007, p. 35 - grifos do autor). Isso nos coloca de forma mais ampla no campo dos estudos sobre os gêneros discursivos, evidenciando que a atividade socialmente organizada, assim como o discurso, se realiza por meio de gêneros, ou seja, de forma relativamente estável (BAKHTIN, 2011; CLOT, 2007; LIMA, 2016c). Na definição de Clot (2010):

O gênero é, de algum modo, a parte subentendida da atividade, o que os trabalhadores de determinado meio conhecem e observam, esperam e reconhecem, apreciam ou temem; o que lhes é comum, reunindo-os sob condições reais de vida; o que sabem que devem fazer, graças a uma comunidade de avaliações pressupostas, sem que seja necessário reespecificar a tarefa a cada vez que ela se apresenta (p. 121-122).

Sendo assim, podemos verificar que o gênero de atividade possui uma parte estável, que é coletiva e composta de prescrições que funcionam como "uma 'senha' conhecida apenas por aqueles que pertencem ao mesmo horizonte profissional" (CLOT, 2007, p. 41). Isso significa que não é necessário que o sujeito crie do zero cada ação a cada vez que a realiza, assim como, no caso dos gêneros do discurso, "não enfiamos as palavras, não vamos de uma palavra a outra mas é como se completássemos com as devidas palavras a totalidade" (BAKHTIN, 2011, p. 292). Afinal, já há maneiras socialmente conhecidas de realizar um enunciado em uma dada esfera social e, assim como aponta Clot (2007), de realizar uma atividade. Nas palavras do autor, "se fosse necessário criar, a cada vez na ação, cada uma de nossas atividades, o trabalho seria impossível. O gênero da atividade assenta, portanto, em um princípio da economia da ação" (CLOT, 2010, p. 121).

\subsection{Estilo, comportamento e desenvolvimento}

Passamos agora ao aspecto relativo do gênero, que fica a cargo da subjetividade de cada indivíduo que o emprega. Isso ocorre porque "todo enunciado [...] é individual e por isso pode refletir a individualidade do falante (ou de quem escreve)" (BAKHTIN, 2011, p. 265), sendo essa premissa também válida para o gênero de atividade (CLOT, 2010; 2007). A relação 
entre estilo e gênero se dá quando, ao realizar determinada atividade, o sujeito opta por uma variante pertencente a um gênero de atividade daquela esfera social, isto é, escolhe um modo de agir comumente conhecido e dado pela sociedade, mais precisamente por um coletivo. Mas, ao empregar essa variante, ele também a recria ou a estiliza de acordo com sua memória pessoal e a situação concreta na qual age. Em outros termos, o indivíduo se vale de uma memória transpessoal, que é o gênero, e a recria de acordo com sua individualidade. Assim, a atividade real é construída na tensão entre duas memórias, uma pessoal e outra transpessoal (CLOT; FAÏTA, 2016).

Desse modo, a distância entre o prescrito e o realizado, apontada no subitem anterior, se dá pelas situações concretas de realização e pelo emprego da dimensão pessoal na atividade, ou seja, ocorre por meio da estilização. Segundo Clot, o estilo na atividade "é, antes de mais nada, a transformação do gênero na história real das atividades no momento de agir em função das circunstâncias" (2010, p. 126). Por isso, quando a atividade é colocada em ação por um indivíduo, como, por exemplo, a atividade docente em sala de aula, o gênero fica carregado de individualidade do sujeito, pois o indivíduo, além de repetir as formas prescritivas do gênero, também as recria (BAKHTIN, 2011; CLOT, 2010).

Como veremos a seguir, o estilo corresponde à flexibilidade necessária para a existência e desenvolvimento da atividade, pois a cada mudança do meio é preciso atualizar o gênero para que este continue eficiente e eficaz na proporção que lhe cabe na organização social. Nas palavras de Clot (2007, p. 18), "a subjetividade na ação profissional não é um ornamento ou uma decoração da atividade. Ela está no princípio de seu desenvolvimento”.

Para compreender essa flexibilidade voltamo-nos agora para Vigotski, autor fundamental na base teórico-metodológica da Clínica da Atividade Docente. Segundo o autor, o comportamento é um processo de equilíbrio do organismo com o meio. No entanto, "nunca se pode admitir que essa equilibração se realize até o fim de maneira harmoniosa e plena, sempre haverá certas oscilações da nossa balança, sempre haverá certa vantagem da parte do meio ou do organismo" (VIGOTSKI, 1999, p. 311). Tendo em vista esse processo de equilibração, a atividade do sujeito deve estar sempre em renovação para atender às necessidades do desenvolvimento do meio, assim como quando buscamos o equilíbrio de uma balança. Se persistirmos nessa metáfora, podemos dizer que quando o meio, ou seja, as situações sociais concretas se modificam, o outro lado da balança, que corresponde ao sujeito, 
também deve se modificar a fim de garantir a tentativa da estabilidade em relação ao meio. É nesse processo de equilibração que a subjetividade e o estilo entram em jogo na realização da atividade, justamente nessa tentativa do indivíduo de responder às dificuldades do meio, ou seja, de equilibrar a balança.

Ainda sobre o comportamento humano e sua relação com o meio, buscamos compreender a forma como ocorre esse processo de equilibração evidenciado por Vigotski (1999). Para dar conta dessa problemática, nos valemos do conceito de atividade reguladora (LIMA, 2010), o qual apresenta a trajetória desse processo de equilibração. De acordo com LIMA (2010), a atividade reguladora consiste em um processo de "reestruturação de uma atividade que acaba de esbarrar em uma dificuldade” (2010, p. 207). Essa dificuldade advém do meio, aqui entendido não só como as condições materiais, mas também como as relações sociais. Para se reestruturar, ou seja, tentar entrar em equilíbrio com esse meio que lhe impõe dificuldades, o sujeito, segundo Lima (2010), quando motivado por uma intenção de agir, produz um comportamento que oscila entre dois extremos, "dois pólos opostos, correspondentes a dois motivos antagonistas ou contraditórios, até que estabeleça entre eles um relativo equilíbrio", como em uma síntese dialética (LIMA, 2010, p. 207).

Após os apontamentos acima, de que todo comportamento humano é uma tentativa de equilíbrio do organismo em relação ao meio, podemos compreender que o gênero não pode ficar restrito a prescrições imutáveis, pois isso impossibilitaria o desenvolvimento do sujeito, do coletivo e do meio, dada a relação dialética entre essas três instâncias. Sobretudo, nesse sentido, os gêneros não são estáveis, mas de fato relativamente estáveis (BAKHTIN, 2011).

Podemos ir além dessas ideias fundamentais e afirmar que, ao contrário de duas coisas disjuntas, há uma relação necessária entre, de um lado, o individual e o estilo e, de outro, o coletivo e o gênero. Sobre isso, Clot (2010) afirma que a capacidade de enriquecer o gênero por meio do estilo pode transformar a experiência individual em experiência coletiva. Isso significa que o estilo, que, em um primeiro momento, é individual, pode vir a ser parte do gênero, garantindo sua eficácia/vitalidade. 


\subsection{Estilo e poder de agir}

De acordo com os pressupostos teóricos da Clínica da Atividade Docente (cf. LIMA, 2016a), a recriação da atividade é um processo que pode se atrofiar, levando o sujeito a se aproximar de uma repetição da atividade praticamente ao idêntico (LIMA, 2010, p. 237). No entanto, não é possível apenas repetir a atividade de outrem, pois o que há são sujeitos agindo com maior ou menor grau de estilização, ou recriação. Nessa ótica, vale observar que, segundo Clot, "uma atividade produtiva comum que se fecha para esse trabalho de re-criação não é normal mesmo que, atualmente, ela seja frequente" (2010, p. 23), ou seja, por mais que esse grau quase "zero" de recriação ocorra até mesmo com alguma frequência na atividade diária, por exemplo, dos trabalhadores da educação, isso não é considerado benéfico para sua saúde (cf. LIMA e ALTHAUS, 2016), pois, na perspectiva vigotskiana adotada por Clot, "o sujeito se constrói apenas quando começa a empregar, a seu respeito e à sua maneira, as formas de condutas que os outros haviam utilizado previamente, em relação a ele para agir no objeto" (2010, p. 23).

Esse "empregar à sua maneira" corresponde à individualidade, ao estilo, que, segundo Clot (2010), está diretamente relacionado ao poder de agir do sujeito em sua própria atividade. Para a Clínica da Atividade, o poder de agir é um ponto central para a saúde do trabalhador, pois consiste em "poder aí desenvolver suas atividades, seus objetivos, instrumentos e destinatários, afetando a organização do trabalho por sua iniciativa" (CLOT, 2010, p. 8 - grifos do autor).

Podemos agora estabelecer uma relação entre estilo e poder de agir. Afinal, viver no trabalho para o sujeito é afetar por sua iniciativa o que lhe é prescrito no cenário de execução de sua atividade. Em outras palavras, o estilo é fonte de seu poder de agir, pois quando o agente realiza a sua maneira o que lhe é prescrito, diante das dificuldades da situação concreta de trabalho, recria e então afeta de alguma forma a organização do seu próprio trabalho. Caso contrário, se o sujeito fracassa e não desenvolve a seu modo as condutas que os "outros haviam utilizado previamente" (CLOT, 2010, p. 23), ele também não afeta seu meio de trabalho e as ações ocorrem independentemente de sua iniciativa. Ou seja, "a pessoa age, mas não se sente ativa" (CLOT, 2010, p. 8). Isso resulta na depreciação do trabalhador, que não vê a eficácia da sua própria ação, resultando em perdas emocionais. 
Mesmo diante da importância da faceta individual no trabalho, como traçado acima, não se pode negar a importância da faceta social da atividade. Não há, de forma alguma, entre essas duas instâncias uma independência, pois "o não domínio do gênero e de suas variantes impede a elaboração do estilo" (CLOT; FAÏTA, 2016). Com efeito, é o domínio das variantes já dadas no social que liberam o sujeito para aplicar a elas sua individualidade, sua memória pessoal.

Nesta fase final de discussão de nossa fundamentação é possível visualizar uma estreita relação entre gênero, estilo e desenvolvimento subjetivo. Assim, trataremos de elucidar essa questão na análise dos dados. Com esse intuito, neles buscaremos a compreensão de como se dá na prática, em sala de aula, a flexibilidade do gênero de atividade docente, que é coletivo e, ao mesmo tempo, constituído pela iniciativa de indivíduos que o colocam em ação.

\section{Análise de dados}

A análise tratará de dois trechos de diálogo nos quais os professores verbalizam as dificuldades do planejamento, ou do previsto, e de seu respectivo desenvolvimento em aula, isto é, de sua realização. Para darmos conta desses dois trechos, organizamos nossos dados em dois subitens. Cada um deles é dedicado à fala de um professor e, colocados em paralelo, reúnem semelhanças de temáticas levantadas pelos docentes. Afinal, tanto na fala do professor "A" quanto na do Professor "B" é discutida, entre docente e pesquisadores, a função do planejamento e dos improvisos no exercício da docência. Essa temática é motivada pelos trechos de aula em vídeo selecionados ${ }^{2}$ para a realização da autoconfrontação simples, nos quais os professores aparecem utilizando exemplos do cotidiano, não planejados a priori, para explicar conceitos teóricos para seus alunos.

\subsection{Trecho de diálogo com o Professor "A"}

No trecho apresentado abaixo, podemos observar que o professor compartilha uma de suas dificuldades ou preocupações, que é o trajeto seguido por sua aula. Como podemos conferir:

\footnotetext{
${ }^{2}$ Foram dois os trechos selecionados, um da aula do Professor "A" e outro da aula do Professor "B". Isso corresponde à sexta etapa de realização da autoconfrontação simples, explicada no item "metodologia" deste trabalho.
} 
$\mathrm{P}^{3}: \quad$ como você vê a ideia de planejar os exemplos dados em sala de aula?

$\mathrm{PA}^{4}$ : Todo planejamento é bem-vindo. Mas a aula não é perfeita [...] [numa] sequência, tudo certinho, assim. Porque os alunos também vão caminhando [...] [e] você tenta acertar o alvo, vamos dizer assim. Mas o trajeto dá umas pequenas desviadas. [...] Acontece muito isso. Nessa aula até [...] acho que não aconteceu porque estava sendo filmada, porque é normal o aluno dar uma desfocada. Situações essas em que você vai desviandinho [do trajeto da aula] porque um [aluno] coloca uma situação, [em outro] momento outro [aluno] coloca outra. [Os] alunos [...] citam muita coisa, por exemplo assim: "mas, não, na minha empresa, onde eu trabalho, é tal coisa", "eu vivencio uma realidade diferente do que o senhor fala em sala de aula, professor, como que eu faço?” Isso é comum, inclusive uma das filmagens nossa lá traz. Não foi filmagem, [mas] foi uma aula que vocês assistiram, o aluno colocou sobre liderança: "na minha empresa, olha, eu tenho casos assim, assim e tal" [..]. A gente vê isso acontecer muito. [...] Acho que pelo fato de vocês estarem em sala de aula isso não [...] apareceu da forma com que é cotidiano nosso. Então a gente planeja. [O planejamento] é bem-vindo, mas também eu não posso engessar. (L. 584-599) $)^{5}$

A dificuldade em manter o curso planejado da aula é verbalizada após o pesquisador perguntar sobre a possibilidade "de planejar os exemplos dados em sala de aula". Em resposta o Professor afirma que "todo planejamento é bem-vindo", mas observa que planejar não é o suficiente porque, em suas palavras: "a aula não é perfeita [...] [numa] sequência, tudo certinho, assim. Porque os alunos também vão caminhando [...] [e] você tenta acertar o alvo”.

Nesse trecho o Professor verbaliza como se dá, na prática, a distância entre o prescrito e o realizado, ou seja, entre o que é planejado e o que ocorre em sala de aula. Nesse caso específico, o que os diferencia é a atitude ativa dos alunos, pois quando participam da aula, levantando situações por

\footnotetext{
${ }^{3}$ Sigla referente ao pesquisador condutor do Método.

${ }^{4}$ Sigla referente ao professor participante do Método.

5 “L. 584-599” corresponde à extensão das linhas do trecho transcrito em análise e à sua localização no arquivo geral da transcrição realizada a partir do áudio da autoconfrontação simples.
} 
eles vivenciadas em seu dia a dia nas empresas nas quais possivelmente trabalham, acabam por levar o trajeto da aula a dar "umas pequenas desviadas". Ressaltamos que os motivos que resultam no distanciamento entre o esperado/prescrito e o que se realiza podem ser os mais diversos, pois essa distância é provocada justamente por condições do meio.

Podemos conferir nas palavras do Professor que o planejamento tem sua devida importância. Segundo ele, "todo planejamento é bem-vindo", mas se torna indispensável adaptá-lo conforme as exigências do meio, conforme levantado em nossa fundamentação teórica. Diante dessa problemática, entre o planejado e/ou esperado e o curso real que a aula toma, o Professor possivelmente recorre ao improviso, ou seja, a realização de algo sem preparação prévia, feito na própria ocasião, no momento. Essa decisão de realizar um improviso poderia talvez vir a prejudicar o desenvolvimento da aula planejada, caso olhássemos o trabalho docente apenas como execução do prescrito. No entanto, como colocado em nosso referencial teórico, o trabalho humano vai além da prescrição. Sendo assim, esse improviso, em certas situações, pode não prejudicar, mas colaborar para que a aula não fique, de acordo com as palavras do próprio docente, "engessada".

Ainda nesse trecho, verificamos que o Professor resolve um conflito existente entre duas diferentes situações possíveis em sala: de um lado, o perigo da ausência do planejamento e, de outro, o da aula "engessada", que não foge do planejamento mesmo quando se torna necessário por demanda dos alunos. É exatamente dentro desse conflito que as escolhas dele, como sujeito ativo em sua atividade, revelam sua subjetividade e capacidade de modificar o meio por própria iniciativa, ou seja, pelo estilo. Em outras palavras, o estilo de sua prática se revela. Afinal, sigo com o meu plano ou atendo as expectativas momentâneas de meus alunos? Notamos que o professor já resolveu essa dificuldade optando por não engessar a aula, mesmo tendo como consequência que "o trajeto" possua "umas pequenas desviadas". Ele menciona: "então a gente planeja. [O planejamento] é bemvindo, mas também eu não posso engessar". Podemos então conferir que há um relativo equilíbrio estabelecido entre os dois extremos possíveis, pois não há grandes desvios em relação ao planejamento, apenas "pequenas desviadas". Isso garante, ao mesmo tempo, uma aula que segue uma linha traçada pelo planejamento, mas não engessada. 
Dessa forma, podemos ver na prática de sala de aula a busca do equilíbrio definido por Vigotski (1999), que é o do sujeito com seu meio. Essa busca de estabilidade advém, de um lado, como resposta a uma prescrição da atividade docente, a de que uma aula deve ser planejada, e, de outro, dos obstáculos do meio, que nesse caso se apresentam pela participação dos alunos com exemplos de seus respectivos cotidianos empresariais. Sendo assim, quando o Professor nos coloca que "a aula não é perfeita [...] [numa] sequência, tudo certinho, assim. Porque os alunos também vão caminhando [...] [e] você tenta acertar o alvo, vamos dizer assim. Mas o trajeto dá umas pequenas desviadas", ele responde a essa prescrição do planejamento, garantindo que sua aula não se desvie totalmente e atendendo, dessa forma, à ementa da disciplina, ou seja, à prescrição. Porém, por outro lado, não nega a participação de seus alunos, que em alguns casos podem mudar em algum grau o percurso dos estudos.

Essa busca pelo equilíbrio se realiza por escolhas do sujeito que tenta, por meio de diferentes combinações estilísticas, atender às demandas do meio. Para isso o sujeito recorre ao estilo, ou seja, toma os recursos do gênero ao mesmo tempo que os recria para responder às demandas que lhe são impostas. Nas palavras do próprio professor: "a gente busca acertar o alvo", o que revela um esforço para superar um conflito já mencionado entre o planejamento e as demandas que aparecem durante a aula e evidencia o que LIMA (2010, p. 207) conceitua como atividade reguladora, que é justamente esse processo de oscilação ininterrupta entre dois extremos até uma aproximação de equilíbrio entre eles.

Essa oscilação dialética, segundo Lima (2010), faz parte de uma atividade reguladora, que corresponde a um processo que envolve o sujeito no momento em que se propõe a dominar um gênero de atividade. Para compreendermos isso na prática docente, utilizamos a situação mencionada pelo professor e vislumbramos dois cenários possíveis, que estão no extremo das condições por ele apontadas. No primeiro, há uma total inflexibilidade do plano de aula, o professor evita qualquer ação que possa comprometer aquilo a que se propôs a fazer em sala. No segundo, há uma total flexibilidade no planejamento, o que acaba resultando em uma aula que possivelmente não atenderá à ementa do curso. É entre esses dois extremos que o Professor busca a mínima oscilação, ou seja, achar um ponto de equilíbrio entre o planejado e o não-planejado/imprevisto, garantindo assim um pouco de flexibilidade, mas também o cumprimento do que se espera. 
Essa busca de "acertar o alvo" revela que o mestre está engajado em desenvolver sua prática docente e, com esse objetivo, procura resolver os embates resultantes da realização de sua prática. O sujeito "experimenta", então, ao longo de sua experiência de ensino-aprendizagem, diferentes combinações de gestos pertencentes ao gênero de atividade docente e, ao mesmo tempo, os recria de acordo com as situações que enfrenta em sala, de um lado, e com o que lhe é prescrito, de outro. Tanto essa recriação quanto suas diferentes combinações correspondem ao estilo. Assim, se no enunciado o estilo equipara-se ao meio linguístico (BAKHTIN, 2011, p. 302), na atividade o estilo equivale ao meio linguístico e extralinguístico que o sujeito combina, recombina e recria para realizar determinada atividade.

\subsection{Trecho de diálogo com o Professor "B"}

No trecho abaixo, o professor compartilha sua estratégia para que conceitos teóricos não sejam abstratos para seus alunos. Como podemos conferir:

$\mathrm{P}^{6}: \quad$ Mas a quem ajudam esses improvisos?

$\mathrm{PB}^{7}$ : Me ajudam. Me sinto [...] mais seguro com aquele conceito. Uma coisa que me preocupa é passar um conceito muito teórico. Os cursos de engenharias e tecnologias são cursos aplicados e, [por isso], têm que estar sempre se preocupando em inserir um conteúdo que [o aluno] possa eventualmente, potencialmente utilizar. Engenheiro não se sente bem trabalhando com algo puramente abstrato. Isso é uma questão de formação mesmo. Eu acho que para os alunos ajuda [também], porque eles conseguem enxergar. Eles têm a mesma formação, são engenheiros mecânicos. Eles estão quase formados já. Eu acho que ajuda nesse sentido. Na verdade tem que ouvir eles, não sei se vocês têm essa [intenção], mais essa etapa de conversar com [...] os alunos (L. 144-153). ${ }^{8}$

\footnotetext{
${ }^{6}$ Sigla referente ao pesquisador condutor do Método.

${ }^{7}$ Sigla referente ao professor participante do Método.

8 “L. 144-153” corresponde à extensão do trecho transcrito em análise e à sua localização no arquivo geral da transcrição realizada a partir do áudio da autoconfrontação simples.
} 
Como podemos observar, o pesquisador questiona a quem os improvisos ajudam. O docente responde que lhe ajudam, na medida em que se sente "mais seguro" quando vai explicar um "conceito", pois há uma preocupação para não "inserir um conteúdo" puramente teórico, que não tenha ligação com a prática. Essa preocupação é motivada, nas palavras do próprio Professor, pelo fato de que os alunos de engenharia "não se sentem bem trabalhando com algo puramente abstrato" e isso se deve a "uma questão de formação" específica dos discentes do referido curso.

Podemos relacionar essa "segurança" que o professor menciona com o repertório de estilos do gênero profissional docente que ele desenvolveu e que lhe possibilita, mesmo em situação de dificuldade, empregar livremente o gênero de atividade docente, pois, como afirma Bakhtin, "quanto melhor dominarmos os gêneros tanto mais livremente os empregamos, tanto mais plena e nitidamente descobrimos neles a nossa individualidade (onde isso é possível e necessário)" (2011, p. 285).

É possível relacionar a "tranquilidade" que o professor menciona à "liberdade" no emprego do gênero, o que possibilita expor sua individualidade, que se releva dentre outras ocasiões quando escolhe dar um exemplo do cotidiano das empresas para os alunos compreenderem a matéria. Afinal, o estilo já se constitui no próprio exemplo escolhido pelo sujeito docente em detrimento de outros, que em diferentes medidas também auxiliariam seus alunos a compreender a matéria. Ou seja, ele faz uma escolha de uma ação dentre várias outras possíveis no âmbito do mesmo gênero, revelando e descobrindo assim sua individualidade.

Por essa razão, mesmo em uma situação não planejada, como nesses improvisos em que o Professor dá um exemplo do cotidiano para os alunos aprenderem alguns conceitos da matéria, ele se diz "tranquilo" porque esses exemplos possivelmente afetam o principal e imediato destinatário da atividade docente, que é o aluno. Isso se confirma logo após o momento em que o professor ressalta que os improvisos o ajudam, pois se sente "mais seguro" em sala de aula. Ele também afirma que "ajudam" aos alunos. Sendo assim, podemos sugerir que essa tranquilidade mencionada pelo professor advém de sua capacidade de agir, afetar seu meio, quando, ao escolher um exemplo, realiza uma ação que afeta o aluno, ajudando-o a compreender o tópico em questão. 
Em síntese, notamos que para responder a uma necessidade do meio, a de os alunos compreenderem conceitos mais teóricos, o professor faz uma escolha, dentre muitas possíveis, e, por atender a essa necessidade, diz que se sente "mais mais seguro". Dessa maneira, ele responde a um conflito em sua atividade, o qual diz respeito a como explicar um conceito de uma forma que não fique abstrata, tendo em vista que o "engenheiro não se sente bem trabalhando com algo puramente abstrato".

É importante salientar que o estilo não corresponde a algo totalmente inovador da parte do sujeito, mas corresponde a suas escolhas dentro de um campo de possibilidades gerado pelo gênero e aos possíveis retoques nele realizados para atender às demandas do meio. Para Clot (2007, p. 51), o estilo na análise do trabalho é a "reformulação do gênero" no momento de sua execução. Em outras palavras, para o autor, com base clara em Bakhtin (2015), "o gênero é sempre o mesmo e outro, sempre velho e novo ao mesmo tempo” (p. 121), ou seja, é recriado, reformulado constantemente.

Nesse trecho, assim como no do primeiro subitem desta seção, podemos evidenciar um processo de equilibração do organismo com o meio (VIGOTSKI, 1999), e a existência da atividade reguladora (LIMA, 2010). Nesse caso, os extremos são, de um lado, explicar um conceito de uma forma majoritariamente teórica e, de outro, majoritariamente concreta e/ou prática. A implicação do primeiro extremo já foi exposta pelo professor: os alunos, futuros "engenheiros, não se sentem bem trabalhando com algo puramente abstrato", o que restringe sua compreensão do conceito. A implicação do outro extremo, não verbalizada pelo professor, mas que pode ser vislumbrada por meio desta análise, é que optar por uma explicação puramente prática pode levar a aula mais para a esfera do trabalho operacional, estando assim em desacordo com a formação de um engenheiro. Tanto é que, de acordo com as Diretrizes Nacionais dos Cursos de Engenharia, o aluno dessa área deve desenvolver "conhecimentos científicos, tecnológicos e instrumentais" (MEC, 2002, p. 3). Ou seja, a formação dos alunos não pode ficar restrita às atividades vinculadas à prática concreta profissional. Segundo a diretriz, que é uma prescrição, o aluno precisa ter, em conjunto, o prático e o teórico, ou o abstrato e o concreto. 


\section{Resultados e discussões}

Por meio dos dados apresentados e analisados, foi possível identificar a questão do estilo em cada um dos trechos selecionados para estudo. No primeiro, observamos que o professor se encontra em uma constante tentativa de não permitir que sua aula fique engessada nem perca o foco no conteúdo proposto pela ementa. Os obstáculos que estão invariavelmente presentes em qualquer atividade humana e aos quais o trabalhador docente procura responder (como a dificuldade de manter o curso da aula, havendo de um lado seu planejamento e de outro também as demandas dos alunos) levam à estilização do gênero, a qual ocorre no comportamento humano por meio de um processo de tentativa de equilibração do sujeito com seu meio. Assim, o trabalhador docente se engaja em uma atividade reguladora, oscilando entre dois extremos na tentativa de estabilidade da aula diante dos empecilhos provenientes do meio.

No segundo trecho, vimos que o professor dá, em sala de aula, exemplos improvisados, o que representa uma resposta a uma demanda do meio, ou seja, de seus alunos, pois eles, segundo o docente, "não se sentem bem trabalhando com algo puramente abstrato”. Então, o mestre formula um exemplo no curso de sua atividade com o intuito de deixar um conceito por ele explicado o mais próximo possível de uma situação concreta de trabalho. Dessa forma, não só estaria auxiliando os alunos, mas também ajudando a si mesmo, pois, como menciona, isso lhe traz segurança em sala de aula, a qual advém possivelmente da garantia de uma espécie de resposta a uma preocupação de ensino-aprendizagem que é, em suas palavras, não "passar um conceito muito teórico", uma vez que "os cursos de engenharias e tecnologias são cursos aplicados e, [por isso], têm que estar sempre se preocupando em inserir um conteúdo que [o aluno] possa eventualmente, potencialmente utilizar".

Essas tomadas de decisões com finalidade de superar os obstáculos resultantes da realização da atividade são indispensáveis ao desenvolvimento do sujeito e à eficiência e eficácia do trabalho de ensino-aprendizagem. Assim, é necessário utilizar o estilo como um recurso para garantir o que Clot (2010) denomina poder de agir.

Ao findarmos este estudo, observamos que se a atividade fosse dotada de uma total estabilidade ela jamais se transformaria juntamente com o meio e que, com isso, ficaria comprometida nossa característica 
fundamentalmente humana, que é de nos adaptarmos ao meio ao mesmo tempo que o adaptamos a nós mesmos, sendo por ele também modificados. Assim, "responder às convocações do real continua sendo, sem dúvida, o que há de mais humano no homem” (CLOT, 2010, p. 237).

O levantamento desses comportamentos de estilização do gênero, realizados em sala de aula e verbalizados em situação de autoconfrontação, pode contribuir para o compartilhamento no coletivo docente dessas soluções já encontradas por determinados professores para dificuldades que são na verdade coletivas e gerais. Afinal, no coletivo de trabalhadores no qual esses mesmos sujeitos estão inseridos pode haver alguém que enfrente conflitos muito similares, para os quais ainda não desenvolveu uma solução. Ao se socializarem essas estilizações, por meio da retomada dessas discussões em reuniões pedagógicas, por exemplo, os professores têm a oportunidade de ver em seus colegas comportamentos que podem vir a se constituir como variantes para a realização de seu trabalho e enriquecer o gênero de atividade docente. É que "quanto mais um sujeito tem pontos de contato com essas variantes, mais rico e mais flexível é seu manejo do gênero" (CLOT; FAÏTA, 2016, p. 40).

\section{Referências}

BAKTHIN, M. Estética da criação verbal. Trad. Paulo Bezerra. 6. ed. São Paulo: Martins Fontes, 2011.476p.

BAKTHIN, M. Problemas da poética de Dostoievski. Trad. Paulo Bezerra. 5. ed. Rio de Janeiro: Forense universitária, 2015.341p.

BRASIL. Diretrizes Curriculares Nacionais do Curso de Graduação em Engenharia. Resolução CNE/CES no 11, de 11 de março de 2002. Brasília: MEC-Ministério da Educação, 2002.

CLOT, Y. A função psicológica do trabalho. Trad. Adail Sobral. 2. ed. Petrópolis: Vozes, 2007.222p.

CLOT, Y. Trabalho e poder de agir. Trad. Guilherme Teixeira e Marlene Vianna. Belo Horizonte: Fabrefactum, 2010. 343p.

CLOT, Y.; FAÏTA, D. Gêneros e estilos em análise do trabalho: conceitos e métodos. Trad. Rozania Moraes. Revista Educação e Trabalho, Belo Horizonte, UFMG, v. 25, n. 2, p. 33-60, 2016. 
CONTE, T. R. D. Funções linguístico-psicológicas do assalto ao turno em situação de autoconfrontação cruzada: o trabalho docente em foco. 2017. Dissertação (Mestrado em Letras) - Universidade Tecnológica Federal do Paraná, Pato Branco, 2017.

ECKER, D. A. F. Aspectos do desenvolvimento da experiência docente na educação superior: um estudo sob a ótica da teoria dos gêneros de atividade. 2016. (Mestrado em Desenvolvimento Regional) - Universidade Tecnológica Federal do Paraná, Pato Branco, 2016.

FAÏTA, D. La conduite du TGV: exercices de styles. Champs Visuels, Paris, n. 6, p. 123-129, 1996.

LIMA, A. P. de. Visitas técnicas: interação escola-empresa. Curitiba: Editora CVR, 2010. 265p

LIMA, A. P. de. Clínica da atividade docente. In: Clínica da Atividade Docente. 2016a. Disponível em: < https:// formacaoesaudedoprofessor.com/2016/03/28/clinicada-atividade-docente-uma-proposta-de-formacao-continuada-e-de-promocao-dasaude-do-professor-no-trabalho/>. Acesso em: 5 jan. 2018.

LIMA, A. P. de. Autoconfrontação simples e cruzada: um método clínico para o tratamento da atividade docente. In: Clínica da Atividade Docente. 2016b. Disponível em: < https://formacaoesaudedoprofessor.com/2016/04/06/autoconfrontacaosimples-e cruzada-como-metodo-clinico-de-promocao-da-formacao-continuadae-da-saude-do-professor/>. Acesso em: 5 jan. 2018.

LIMA, A. P. de. Formas relativamente estáveis de atividade docente: o que elas têm a ver com a saúde do professor? In: Clínica da Atividade Docente. 2016c. Disponível em: $<$ https://formacaoesaudedoprofessor.com/2016/03/04/formas-relativamenteestaveis-de-atividade-docente-o-que-elas-tem-a-ver-com-a-saude-do-professor/> . Acesso em: 5 jan. 2018.

LIMA, A.; ALTHAUS, D. Formação docente continuada, desenvolvimento de práticas pedagógicas em sala de aula e promoção da saúde do professor: relações necessárias. Revista Brasileira de Estudos Pedagógicos, Brasília, v. 97, n. 245, p. 97-116, jan./abr. 2016.

LIMA, A.; ALTHAUS, D. Práticas docentes: dialogar, compartilhar e refletir. Pato Branco: UTFPR, 2012. Vídeos disponíveis em: <https://www. youtube.com/watch?v=viR4Glv6bMc > e < https://www.youtube.com/ watch?v $=$ wASTpGiaAb8>. Acesso em: 5 jan. 2018.

LIMA, A.; ALTHAUS, D.; ECKER, D. Exemplos, imprevistos e improvisos no trabalho do professor da educação superior em sala de aula. Ergologia, Société Internationale d'Ergologie, n. 15, p. 109-128, 2016. 
MARCUSCHI, L. A. Da fala para a escrita: atividades de retextualização. 9. ed. São Paulo: Cortez, 2008. 131p.

MOITA LOPES, L. P. (Org.). Por uma linguística aplicada INdisciplinar. São Paulo: Parábola Editorial, 2006. 279p.

PRETI, D. (Org.). Análise de textos orais. 4. ed. São Paulo: Humanitas, 1999. 236p.

SOUZA-e-SILVA, M. C. P. O Professor como Trabalhador. Cadernos de Estudos Linguisticos, Unicamp \IEL, Campinas, n. 22, p. 339-351, 2003.

VIGOTSKI, L. S. Psicologia da arte. Trad. Paulo Bezerra. São Paulo: Martins Fontes, 1999.377p.

VIGOTSKI, L. S. A formação social da mente: o desenvolvimento dos processos psicológicos superiores. Organização de Michael Cole et al. Trad. José Cipolla Neto, Luís Silveira Menna Barreto, Solange astro Afeche. 7. ed. São Paulo: Martins Fontes, 2007. 181p. 